This item was submitted to Loughborough's Research Repository by the author.

Items in Figshare are protected by copyright, with all rights reserved, unless otherwise indicated.

\title{
Developing young adolescents' psychological need satisfaction: a feasibility study of a pupil-focused intervention in secondary schools
}

\section{PLEASE CITE THE PUBLISHED VERSION}

https://doi.org/10.1080/03055698.2020.1719386

\section{PUBLISHER}

Taylor \& Francis

\section{VERSION}

AM (Accepted Manuscript)

\section{PUBLISHER STATEMENT}

This is an Accepted Manuscript of an article published by Taylor \& Francis in Educational Studies on 30 January 2020, available online: http://www.tandfonline.com/10.1080/03055698.2020.1719386.

\section{LICENCE}

CC BY-NC-ND 4.0

\section{REPOSITORY RECORD}

Earl, Stephen R, Carla Meijen, lan Taylor, and Louis Passfield. 2020. "Developing Young Adolescents' Psychological Need Satisfaction: A Feasibility Study of a Pupil-focused Intervention in Secondary Schools". Loughborough University. https://hdl.handle.net/2134/11920818.v1. 


\title{
Developing Young Adolescents' Psychological Need Satisfaction: A
}

\section{Feasibility Study of a Pupil-Focused Intervention in Secondary Schools}

\author{
Stephen R. Earl*a1, Carla Meijen ${ }^{\mathrm{a} 2}$, Ian M. Taylor ${ }^{\mathrm{b}}$, and Louis Passfield ${ }^{\mathrm{a} 3}$ \\ ${ }^{\text {a}}$ School of Sport and Exercise Sciences, University of Kent, Medway, Kent, UK \\ ${ }^{\mathrm{b}}$ School of Sport, Exercise and Health Sciences, Loughborough University, \\ Leicestershire, UK
}

* Address for correspondence to Stephen R. Earl, The School of Education, University of Birmingham, Birmingham, England, UK, B15 2TT.

E-mail: $\underline{\text { S.R.Earl@,bham.ac.uk }}$

\footnotetext{
${ }^{1}$ The present address for Stephen R. Earl is The School of Education, University of Birmingham, Birmingham, UK.

${ }^{2}$ The present address for Carla Meijen is Faculty of Sport, Health and Applied Science, St Mary's University, London, UK.

${ }^{3}$ The present address for Louis Passfield is Faculty of Kinesiology, University of Calgary, Calgary, AB, Canada.
} 


\begin{abstract}
Education-based interventions traditionally focus on the teacher to better support pupils' motivation. Grounded in self-determination theory, the study investigates the feasibility of a pupil-focused intervention to help pupils become more active in their search for basic psychological need satisfaction (BPNS). Focus groups and a two week pupil completed diary-log were administered with 22 UK secondary school pupils from Years 7 and 8 (aged $11-13$ years; $45 \%$ male, $55 \%$ female) and 12 teachers (42\% male, $58 \%$ female). Despite perceived value from teachers, a written diary-log appeared to be ineffective in engaging pupils. Pupil-focused initiatives may benefit from support sessions to provide guidance on pupils' reflections, should be incorporated into normal school practices with a showcase event, and be designed in an interactive electronic format. The study offers theoretical considerations regarding pupils' intrapsychic experience of motivation, and provides teacher and pupil insights into the practicalities of conducting pupil-focused interventions based upon BPNS.
\end{abstract}

Keywords: motivation, psychological needs, diary-log, self-reflection, early adolescence. 
INTRAPSYCHIC PSYCHOLOGICAL NEEDS

\section{Introduction}

A significant aim for educators is to motivate pupils to learn. This can sometimes prove challenging with some pupils seemingly withdrawn from learning activities or only exerting minimal effort at school (Legault Green-Demers, \& Pelletier, 2006). Optimal motivation is posited to flourish when pupils have adaptive intrapersonal experiences within a supportive environment. Educational interventions largely focus on nurturing the latter via teacher training programmes (e.g. Aelterman, Vansteenkiste, Van den Berghe, De Mayer, \& Haerens, 2014), school-based initiatives (e.g. Shannon et al., 2018), or amendments to school policy (see Lawson \& Lawson, 2013). Yet empowering pupil-centred programmes may also be beneficial in nurturing their autonomous motivation for learning by targeting pupils' understanding and awareness of their psychological experiences (e.g., Cleary \& Zimmerman, 2004). Consequently, the present study explores the feasibility of a pupil-centred intervention in early secondary schools based upon pupils' experience of basic psychological need satisfaction (Ryan, \& Deci 2017).

Self-determination theory (SDT) is a theory of human motivation which maintains that individuals' optimal psychological growth and self-determined motivation is dependent on the satisfaction of three basic psychological needs for autonomy, competence, and relatedness (Ryan \& Deci, 2017). Autonomy reflects an individual's experience of volition and psychological freedom so that their behaviour is perceived to originate from themselves (deCharms, 1968). The need for competence reflects an individual's experience of mastery within their environment and perceived effectance in achieving their desired goals (White, 1959). Relatedness reflects the experience of close connection and acceptance from others; that is, to care and be cared for by others (Baumeister \& Leary, 1995). The fulfilment of these needs has been shown to represent the psychological foundation for autonomous motivation, school engagement, better emotional functioning, well-being, and school achievement (e.g., 


\section{INTRAPSYCHIC PSYCHOLOGICAL NEEDS}

Badri, Amani-Saribaglou, Ahrari, Jahadi, \& Mahmoudi, 2014; Ratelle \& Duchesne, 2014; Saeki \& Quirk, 2015). In contrast, frustration of these needs can result in amotivation, school disengagement and ill-being (e.g., Earl, Taylor, Meijen, \& Passfield, 2017; Jang, Kim, \& Reeve, 2016).

Founded on this premise, SDT based interventions have focused on creating social environments that foster learners' psychological need satisfaction. For example, training secondary school teachers to become more autonomy supportive has been found to result in learners reporting positive motivational and academic outcomes (e.g. Reeve, Jang, Carrell, Jeon, \& Barch, 2004; Tessier, Sarrazin \& Ntoumanis, 2010). More recent school-based interventions have been centred upon educating and changing teachers' beliefs towards autonomy supportive strategies (Cheon \& Reeve, 2015), or the combination of autonomy and competence support (e.g., Aelterman et al., 2014). Providing teachers with information on the benefits of need support as well as offering training workshops and group discussions were found to enhance teachers' use of need supportive strategies. In turn, this resulted in pupils reporting improved psychological need satisfaction, autonomous learning, better school grades, higher school engagement, and lower amotivation. Furthermore, teachers were found to be able to maintain the use of these strategies across the subsequent school year (Cheon \& Reeve, 2013).

Despite the clear value of these contextual interventions, psychological need satisfaction is an intrapsychic experience and thus unique to each individual (Deci, Ryan, \& Williams, 1996). It is not the social context per se that results in the fulfilment of the psychological needs but rather the relative and subjective meaning pupils place upon the context (i.e. the functional significance; Ryan \& Deci, 2017). Some pupils may become predisposed to subconsciously facilitate or block their psychological experiences. For instance, some pupils will enter school with tendencies to seek out possibilities for choice, 


\section{INTRAPSYCHIC PSYCHOLOGICAL NEEDS}

interest and information at school that is conducive to need satisfaction. Alternatively, other pupils may adopt a deleterious perspective which predisposes them to experience a lack of need satisfaction as they are inclined to perceive elements of school as pressuring, coercive, or uncontrollable. For pupils who adopt this maladaptive outlook, modifications to a school climate, even if motivationally supportive, may be limited in the extent to which they foster psychological need satisfaction. Raising pupils' self-awareness of opportunities for psychological need satisfaction, so as to increase the likelihood they are inclined towards such occasions, may be an important method of enhancing their school experience regardless of any variation in teachers or learning contexts.

There may be potential caveats relating to entirely context-focused interventions. First, they place sole reliance on the teaching behaviour to develop pupils' motivational orientation and cognitions. Need supportive teaching can be a challenge for many educators to grasp and can be negatively influenced by time pressures, large class sizes, and diverse curriculums (Liu, Wang, Reeve, Kee, \& Chian, 2019; Pelletier, Séguin-Lévesque, \& Legault, 2002; Taylor, Ntoumanis, \& Smith, 2009). To illustrate, previous research found teachers were less familiar with strategies of autonomy support compared to competence support (Aelterman et al., 2013). Additional teacher training initiatives may be required to develop teachers' conscious awareness and consistent use of effective need supportive teaching (e.g., Reeve \& Cheon, 2016). Second, teachers' perceptions of the need support they provide can be out of sync with those of the pupils (e.g. Zeedyk et al., 2003). Correlations between teacher and student perceptions of need support have been found to be small in magnitude (Taylor \& Ntoumanis, 2007), or only congruent regarding the support of autonomy but not competence (Aelterman et al., 2014). Consequently, manipulating the learning context may be ineffective if pupils perceive the context in a different way to that which is intended. 


\section{INTRAPSYCHIC PSYCHOLOGICAL NEEDS}

To supplement the existing contextual interventions, there may be scope to devise an intervention that directly targets pupils' own perceptions and awareness of their psychological needs. Targeting pupil cognitions and experiences, rather than solely academic performance, can represent a powerful tool to change learning behaviour but can often be overlooked within education systems (Yeager \& Walton, 2011). In accord, a growing number of psychological interventions have been implemented in education facilitating pupils' growth mind-sets (e.g., Park, Gunderson, Tsukayama, Levine, \& Beilock, 2016), self-control (Duckworth, White, Matteucci, Shearer, \& Gross, 2016), and attributions (Hudley, Graham, \& Taylor, 2007). To the authors' knowledge, no pupil-focused intervention has been explored based upon basic psychological needs, despite the clear benefits for pupils' psychological and academic development. Thus how to implement such an intervention would be worth investigating.

\section{The present research}

The principal aim of the present research was to test the feasibility of conducting a pupil-focused intervention with young adolescents (11-13 years), based upon psychological need satisfaction. In designing any learning-based initiative, a common problem is getting learners to participate and engage in them (e.g. Grant, Kinnersley, Metcalf, Pill, \& Houston, 2006). Regardless of a theoretical rationale, if the intervention is not practically feasible, or does not have any relevance for the pupils involved, it will be ineffective in imparting the intended psychological awareness (Lyst, Gabriel, O'Shaughnessy, Meyers, \& Meyers, 2005). A pupil diary-log is proposed to provide a method of implementing such an intervention. Diaries are not uncommon in schools, often being used to help pupils record progress with their homework (e.g., Zabrorowski \& Breidenstein, 2011), and may help influence pupils' attitudes and values by initiating internal dialogue that is personally relevant (Walshe, 2013). Diary methodologies have been widely implemented within university 


\section{INTRAPSYCHIC PSYCHOLOGICAL NEEDS}

education to promote students' reflective learning (e.g. Pavlovich, 2007). Akin with selfregulated learning theory (Zimmerman, 2008), the process of self-reflection helps develop a deeper level of learning so pupils have a greater insight into their thought processes and are better placed to adaptively regulate their own learning, self-evaluations and emotions (Ghanizadeh, 2017). Moreover, the process of self-regulation is cyclic whereby selfreflection helps inform learners' approach to learning through enhanced motivational beliefs and goal-setting (i.e. forethought phase) which in turn facilitates better meta-cognition and task performance (i.e. performance phase; see Cleary \& Zimmerman, 2004). Reflective diarylogs have been shown to be useful in developing both learning strategies and cognitive processing of information in young adolescents (e.g. Glogger, Schwonke, Holzäpfel, Nückles, \& Renkl, 2012). The development of positive thought patterns and intentional selfregulation during adolescence has also been associated with higher well-being, positive development and self-identity (Schmid, Phelps, \& Lerner, 2011). The recording of repeated experiences of need satisfaction may help foster more implicit and non-conscious cognitions that are facilitative of autonomous motivation and psychological need fulfilment (Levesque, Copeland, \& Sutcliffe, 2008).

The current study had two key areas of investigation. Firstly, it was sought to identify any practical considerations that may facilitate or hinder pupils' engagement with a diary-log. Both pupil and teacher opinions were obtained to acquire if, and how, a diary-log may be enjoyable, interesting, and practical for pupils to complete. Although pupil perceptions of the intervention are fundamental to its potential effectiveness, teachers must also see a benefit for it to be incorporated into school programmes. The second intention was to explore the general utility of a reflective diary-log with young adolescent pupils. Although self-reflection is emphasised in higher education with adult learners, cognitive and self-regulatory abilities are still maturing during early adolescence (Huizinga, Dolan, \& van der Molen, 2006). It may 


\section{INTRAPSYCHIC PSYCHOLOGICAL NEEDS}

be valuable to nurture psychological awareness during this initial developmental stage as cognitive and motivational regulation have been shown to decline across adolescence and negatively impact school performance (Bakracevic Vukman \& Licardo, 2010). The findings of the present research are intended to inform future implementation of a proposed intervention which could then be used to test if it is effective in enhancing pupils' psychological need satisfaction, and academic performance, at school.

\section{Materials and Method}

\section{Participants}

Participants were 22 pupils from Years 7 and 8 (mean age $=12.36$ years, $S D=0.73$ years; Year $7=10$, Year $8=12$; male $=10$, female $=12)$ and their teachers $(n=12 ; 5$ male, 7 female) from two secondary schools in the UK. Fifty-nine percent of pupils were White English, 18\% were Black African, 9\% were Indian, and 14\% reported other mixed ethnicities. Four pupils were classified as having a special educational need (SEN), which included one pupil with autism, two pupils with a mild-severe learning difficulty and one pupil with a physical disability. Both schools were co-educational institutions, and included pupils ranging from 11 to 18 years of age.

\section{Recruitment}

Prior to the study commencing, ethical approval from the principal researcher's university ethics committee was obtained. A purposive sampling strategy was used to recruit a selective and non-selective school, and recruit pupils from different ability sets across both Year 7 and 8 pupils. Consequently, we aimed to illuminate both similar and unique characteristics between the different school institutions and their respective pupils (Patton, 2002). We adopted an opportunistic sampling approach to recruit teachers by selecting teachers that taught and had direct interaction with the participating pupils. Informed parental consent was received for all participating pupils, and signed informed consent received from 


\section{INTRAPSYCHIC PSYCHOLOGICAL NEEDS}

both teachers and pupils. All teachers, pupils, and pupils' parents were informed that discussions would be audio recorded, treated in strict confidence and anonymity would be protected in the dissemination of any findings.

\section{Procedure}

Based on methods from previous school-based feasibility studies (e.g. Mendelson, Greenberg, Dariotis, Gould, Rhoades, \& Leaf, 2010), a series of preliminary pupil and teacher focus groups were conducted to investigate their initial opinions towards the utility and feasibility of the proposed diary-log. An advantage of focus groups is that they help generate common attitudes, beliefs and experiences that are relevant and applicable within a specific social context (i.e. within schools; Carey \& Asbury, 2016; Stewart \& Shamdasani, 2014). Through enabling group interaction, it was hoped the serial discussions would formulate a greater breadth and depth of information that would inform the utility, and any limitations, of any potential intervention (Cohen, Manion, \& Morrison, 2013). Hence, a perspective of induction was predominately adopted within each group discussion to attempt to identify unforeseen ideas about the effectiveness of the intervention and how it could be implemented within schools in a novel way (Morse \& Mitcham, 2002). These insights could then be collated to help guide the development of a possible intervention that could piloted with the pupils.

Following practical guidelines on the number and size of focus groups (Krueger \& Casey, 2014), six preliminary focus groups were planned (i.e. two teacher and four pupil), after which it would be assessed if a critical mass of data had been obtained. All focus groups comprised of six participants, with the exception of one pupil group which included four pupils, and were led by the principal researcher. In line with the schools' policies, a member of teaching staff was present during pupil discussions, either in an adjacent room or in the background of the specified classroom. A semi-structured interview schedule was developed 


\section{INTRAPSYCHIC PSYCHOLOGICAL NEEDS}

to provide a generic but flexible framework for each group discussion which offered openended questions so teachers and pupils could elaborate on their experiences and opinions.

Pupils with SENs were able to have their personal assistant present in the focus groups to help with translation or understanding of any question, and all questions were asked in a child-friendly manner. Each focus group was structured into three distinct sections; (1) discuss the potential value of the diary-logs; (2) identify any potential barriers to conducting the intervention; (3) gain practical suggestions that may need to be implemented. On average, pupil discussions lasted approximately 45 minutes and teacher discussions lasted approximately one hour.

Following these preliminary focus groups, the next phase was to pilot a version of the diary-log with pupils. Suggestions from the preliminary focus groups were included in the trialled version of the diary-log but some, such as creating an electronic application, were unfeasible given the limited timescale. Consequently, a written paper version of the diary-log was trialled with pupils for two weeks. Pupils were briefed on the aim of the diary-log and how to complete them. To ensure pupils of all reading levels could complete the diary, written instructions regarding how to complete the diary were provided at the beginning of each diary-log, as well as explained verbally and demonstrated in person prior to pupils trialling the diary-log. Pupils were able to record activities for each day of the two-week period. It was explained to pupils they could complete the diary-log for as many days as they wished (an example of these pupil instructions and diary-log are available in online supplementary information). Diaries were presented in a coloured folder, which could be personalised however pupils wished. Teachers were instructed that they could promote, or not promote, the dairies in any way they desired. The research investigators had no contact with pupils during this two-week pilot. 


\section{INTRAPSYCHIC PSYCHOLOGICAL NEEDS}

The diary-log for each day was structured into two sections; one relating to competence satisfaction whereby pupils reported activities they felt they did well, and the other relating to relatedness satisfaction whereby pupils reported activities where they felt connected with others. For both sections, subsequent boxes were provided for pupils to record their feelings during each activity and the reasons they perceived this to be the case. Given the concept of autonomy is complex and multifaceted (e.g. see Katz \& Assor, 2007; Reeve, Nix, \& Hamm, 2003), rather than pupils trying to record activities where they experienced autonomy, the intervention attempted to foster pupils' autonomy satisfaction by providing them freedom to record experiences that were personally relevant and meaningful to them, and in a manner of their preference (e.g., written notes, drawings, or photos). To avoid pupils feeling coerced, it was stressed to pupils that the diaries would not be assessed and they were free to use the diary-log as much as they desired, without repercussions if they did not complete it. Furthermore, psychological need satisfaction can be influenced by a multitude of contexts (Milyavskaya \& Koestner, 2011), thus pupils were free to log any activity they wished (e.g. school, extra-curricular, and leisure time activities). The premise was for pupils to only record positive experiences of psychological need satisfaction, rather than more deleterious experiences of need frustration. Pupils were instructed that the diaries would be collected at the end of the two weeks, the content would be reviewed by the principal researcher and that it would not be seen by the school or their teachers.

The final phase involved conducting follow-up focus groups to acquire pupil and teacher feedback on the diary-logs. These focus groups followed the same procedure as the first set of focus groups, with the exception that pupils were asked to complete a short questionnaire at the beginning of these follow-up discussions. These questionnaires provided quantitative data on pupils' perceived difficulty and enjoyment of the diary-log, the time of day they completed the diary-log, the type of activities they recorded, and any future 


\section{INTRAPSYCHIC PSYCHOLOGICAL NEEDS}

preferences. As many teachers were not involved in the two-week pilot of the intervention, teacher follow-up discussions were typically smaller in size and shorter in duration (between $20-40$ minutes). These follow-up discussions were designed to find out how pupils generally found the diary-logs, any issues they experienced, and any modifications that would make the diaries easier to complete, more appealing, and more practical. Teachers were also asked if, and how, they may promote the diary-log within schools.

\section{Data Analysis}

In the first instance, the principal researcher listened to and transcribed the discussions from each focus group to identify common themes from the data. Subsequently, these transcriptions were examined by additional members of the research team to confirm agreement over these common themes (Campbell, Quincy, Osserman, \& Pedersen, 2013). These themes were also explained and discussed with teachers and pupils at the end of the follow-up focus groups to ensure their opinions had been comprehensively captured in the study findings (Birt, Scott, Cavers, Campbell, \& Walter, 2016). Such a thematic analytical approach is particularly suited to the present study given the aim of exploring the feasibility of our intervention, rather than examining complex theoretical questions that require higher degrees of interpretation (Krueger \& Casey, 2014; Vaismoradi, Turunen, \& Bondas, 2013). After the two week pilot, the principal researcher collected the diary-logs and examined them in regards to the number of days that contained content and the quality of this content. The quality of the diary-log content was rated in relation to the extent that pupils provided a detailed description of each respective activity, indicated specific feelings, and considered the perceived reasons for these feelings. A diary-log entry was rated poor in quality if there was minimal description of the activity or feelings, with no reflection on the reasons for these feelings.

\section{Results}

\section{Perceived Utility of the Diary-log}


INTRAPSYCHIC PSYCHOLOGICAL NEEDS

Preliminary discussions suggested that enhancing pupils' own awareness of their psychological needs was relatively novel for teachers and pupils, Initially, both emphasised contextual factors as central for pupils' experiences at school (e.g. teacher feedback, role models, social comparisons, or ridicule from others). Yet, after being introduced to the pupilfocused intervention, teachers conveyed value in pupils becoming more self-reliant in their search for positive psychological experiences when faced with contextual dynamics. One teacher said "It is a good idea to get them to think as their own individual", while another explained 'to build these skills (pupils' awareness of their psychological needs) they are going to come from so many different places....if pupils can highlight the areas, and be aware of the areas, at least if they want to, they can do or try to do something about it". Some pupils suggested they "often forget a lot of the good things they do" and the diary-log may help them "focus on the positives" and reflect more each day as they do not usually get the opportunity.

\section{Pupil Completion of the Diary-log}

Overall, $82 \%$ of pupils returned their diary-logs at the end of the study with the pupils $(n=4)$ who did not return their diary-logs coming from the same school. Of the returned diaries, $61 \%$ included content for 11-14 days, whereas $22 \%$ had no days completed or attempted. Figure 1 depicts the rating of pupil diary-logs in regards to the quality of written content and reflection. An example of good quality was "I found out I got a good mark in one of my maths papers. I felt happy and proud - as I did better than my last two results" (i.e. competence satisfaction) and "In class I helped my partner with their classwork. I felt pleased and supportive - they didn't know how do the work and it was nice to help them" (i.e. relatedness satisfaction). Such diary entries attempt to give detail about positive aspects of an activity, outline specific feelings, and provide particular reflection on why the activity may associate with the corresponding feelings. An example of poorer quality was "Cricket. Felt 


\section{INTRAPSYCHIC PSYCHOLOGICAL NEEDS}

OK, it was fun" and "English, Felt OK". These entries offer a generic statement of an activity with scarce, or no, reflection of their experiences and the corresponding link with aspects of the activity. Examination of the returned diaries found that the type of activities that pupils recorded varied between school tests and group work (55\%), sport (41\%), after-school clubs (14\%), and family and friends (9\%).

A concern for teachers was that pupils may struggle to reflect on their psychological experiences and subsequent feelings. One teacher explained that pupils "probably reflect naturally, but when it comes to using that next time to change this or that, I think that is the bit that is missing". Another teacher expressed "they (the pupils) have a quite narrow definition of things....reflect may just mean remember". A pupil mirrored this view explaining the diary-log only made them aware of their experiences when completing it but not in-between diary-log entries. Some pupils expressed a desire to record negative experiences because they were more likely to fabricate positive activities, or not complete the diary-log at all, in the event that they had a bad experience. One pupil commented "if I had a bad day, I would look at the diary and not write anything", whereas another said "on a bad day, I just wouldn't write anything and may make things up". A teacher indicated pupils may not actually be reflecting, expressing "the misleading thing is they are conscientious, they may have filled it in, but made stuff up".

\section{INSERT FIGURE 1 HERE}

In addition, pupil discussions conveyed that the large written boxes for writing were confusing, boring, and appeared too much work, with $14 \%$ of pupils reporting they found the written diary-log hard to complete. The specification of two school lessons and a leisure activity was found to be restrictive as pupils had numerous activities outside of school they wanted to write about (e.g. sport, music, or time with friends). Furthermore, $73 \%$ of pupils reported they would prefer an electronic mobile app version of the diary-log. This was the 
INTRAPSYCHIC PSYCHOLOGICAL NEEDS

300

301

302

303

304

305

306

307

308

309

310

311

312

313

314

315

316

317

case for every pupil in the school that regularly incorporated electronic learning devices into school activities. Particularly prevalent for younger pupils (i.e. 11-12 year olds) was a lack of enjoyment of the written version $(n=82 \%)$ and a preference for an electronic app $(n=$ $100 \%)$.

The extent pupils reported they remembered to complete the diary-log is illustrated in Figure 2. The majority of pupils expressed the diary-log "was difficult to remember" and $14 \%$ reported they never remembered. One pupil said the diary-log “wasn't too much work, the work was remembering". A number of pupils explained they would complete numerous diary-log entries retrospectively if they had forgotten to complete the diary-log. Figure 3 portrays when pupils completed the diary-log with $96 \%$ reporting they did so after school or in the evening when they remembered or had spare time. A concern from teachers was that pupils would not perceive any salient benefit, voicing the diary-log would need to seem relevant to pupils and allow them to see a degree of progression or improvement through their use. This seemed evident after the trial as pupils expressed they struggled to complete the diary-log independent of any other incentive (e.g., school achievement points which could be exchanged for monetary awards). One pupil commented "I know it has meaning to you (the researcher) but to us it is just a diary" whereas another indicated they "didn't think there was a point".

\section{INSERT FIGURE 2 \& FIGURE 3 HERE}

\section{Discussion and Future Considerations}

The proposal of a pupil-focused intervention is aimed to help pupils begin to develop an awareness of their own psychological need satisfaction as opposed to simply reacting to environmental influences, such as teaching strategies or the classroom climate. The initial focus group discussions and two week trial of the diary-log indicated that, although teachers and pupils may see potential substantive value in the intervention, a written diary-log may not 


\section{INTRAPSYCHIC PSYCHOLOGICAL NEEDS}

be a practically feasible method of engaging pupils to become more reflective of their psychological need satisfaction. The fact that $40 \%$ of pupils either did not return or complete the diary-log suggests that a number of pupils may have struggled, not enjoyed, or disengaged with the diary-log. Consequently, the findings highlight a number of practical difficulties in using the format of a written diary-log to encourage pupils to become more active in their search for psychological need satisfaction. In addressing these substantive concerns, both teachers and pupils offered a variety of insights into how the future design of a pupil-focused intervention may be modified for implementation in secondary schools. These insights are outlined and discussed in the subsequent sections.

\section{Facilitating Pupils' Self-Reflection}

In accord with initial teacher concerns, the finding that over half of the pupil diarylogs were rated as less than adequate in both the written content $(n=63 \%)$ and quality of reflection ( $n=68 \%$ ) is particularly telling (see Figure 1). These diaries provided sparse detail of the outlined activities, and limited acknowledgement of the connection between any feelings and the respective activity. In addition to pupils' academic progression, school policies aim to promote pupils' personal development towards lifelong and self-regulated learning (Department of Education, 2019). The present findings suggest that relying on the pupils alone to understand the link between their activities and feelings may be unrealistic. Indeed, early adolescence represents a period of development in which essential selfregulatory functions are still maturing, such as cognitive skills (e.g. self-questioning or goal setting) and sense of self (e.g. interests and values; Azevedo, Moos, Johnson, \& Chauncey, 2010; Huizinga et al., 2006).

Teachers and pupils conveyed the need for intermittent sessions to help guide pupils' reflection on their experiences of psychological need satisfaction. Such assistance towards self-reflection may help foster a cyclic process to enhance pupils motivational beliefs, goal- 


\section{INTRAPSYCHIC PSYCHOLOGICAL NEEDS}

setting and, in turn, improve meta-cognitive processes (see Zimmerman, 2008). These sessions may also provide pupils with the opportunity and guidance to develop expressive writing skills about their experiences which can further benefit emotional and cognitive functioning (Travagin, Margola, \& Revenson, 2015). Intermittent guidance may also be essential in helping pupils focus on occasions of psychological need satisfaction even when this may be challenging. Reflecting on negative experiences can be less beneficial during early adolescence (McLean, Breen, \& Fournier, 2010), and there may be scope to help pupils reflect on any negative experiences in a more constructive manner. The important objective being that pupils understand their self-perceptions, informed by a greater self-awareness, influence their feelings and behaviours more so than their actual ability.

A pupil-focused initiative is not proposed as an alternative to existing contextual interventions (e.g. Cheon \& Reeve, 2015; Reeve et al., 2004), but needs to be used in conjunction with them. Any guidance provided to pupils would need to be provided in an autonomy supportive manner (e.g. Reeve \& Jang, 2006), that offers pupils' structured information (e.g., Hospel \& Galand, 2016) and emotional support (e.g. Ruzek et al., 2016). Both teachers and pupils expressed this guidance would be more engaging for pupils if conducted in informal contexts that were distinct from school classes and may act as a source of feedback and incentive. In particular, pupils expressed that having their effort towards an intervention acknowledged and praised by teachers would be motivating for them. Pupils also indicated that having allocated time at school, and receiving feedback, may help them engage with the intervention as they had expressed that they typically completed the diary-log at home, in the evening, as they were not provided time during school.

\section{Integration with Technology}

In regards to a diary-log, future implementation may be most effective in engaging pupils if presented in an electronic app format. Pupils explained that an electronic app (e.g. 


\section{INTRAPSYCHIC PSYCHOLOGICAL NEEDS}

mobile phone, tablet, or web application) would be more entertaining, accessible, and personable. Teachers also agreed that an electronic format of the diary-log would be appealing to pupils and 'on to a win'. Pupils expressed that recording activities in a variety of methods (i.e. video, pictures, audio, written, and emoji's [animated ideograms]) would help them express how they felt more accurately, and also still allow handwritten diary-log entries to be uploaded onto an electronic database. Moreover, teachers explained the use of an electronic app would reduce the perception of vague boxes of writing and prescribed situations by enabling them to choose options from a drop-down list. There could also be a "free-option" to encourage pupils to think of their own examples.

Given that only a minority of pupils ( $n=22 \%$ ) often remembered to complete the diary-log on a regular basis, it seems unlikely that pupils will get into a habit of using a diary$\log$ if they are not provided with reminders; particularly given the multiple classes and academic requirements they are required to juggle. Pupils explained an advantage of an electronic app is that regular notifications, such as popups and alerts, can appear on their smart device to prompt them to complete their diary-log entry. However, they stated they would want to set their own individual reminders as the diary-log may become annoying, or ignored, if they received notifications at times when they could not complete the diary-log. The trialled written version may have had connotations with school homework, and thus been unappealing for pupils (see Barker \& Weller, 2003); whereas, teachers believed an electronic database of experiences would be easier for pupils to reflect on. Hence, it seems essential any intervention appears like an interactive and non-schoolwork related activity to pupils.

An array of literature has emerged of the possible benefits that interactive apps can have for learning (Martin \& Ertzberger, 2013), metacognition (Ward \& Sweeney, 2015), selfregulation (Johnson \& Davies, 2014) and homework activity (Rawson, Stahovich \& Mayer, 2017). Computers and mobile phone devices offer new possibilities for pupil-focused 


\section{INTRAPSYCHIC PSYCHOLOGICAL NEEDS}

400

401

402

403

404

405

406

407

408

409

410

411

412

413

414

415

416

417

418

419

420

421

422

423

424

learning, enabling teachers more time to focus on enhancing children's thinking rather than solely their understanding of learning material (Stevenson, Hedberg, Highfield, \& Diao, 2015). Modern schools often utilise existing web-applications such as Edmodo.com (which enables interaction between teachers, parents and pupils; see Holland \& Muilenburg, 2011), and ShowMe.com (allowing teachers to share learning videos with pupils; see Spencer, Coutts, Fagan, \& King, 2013). In accord with data protection regulations, care would be needed to ensure the confidentiality of pupils' entries should they desire it, and that information is held securely from public access (Henshaw, 2017).

Disparity also emerged between pupils to the extent they would keep their diary-log personal or share with other pupils, with some indicating they may feel less talented if they compared their diary-log with others. To minimise pupils becoming overly focused on external motives (Ryan \& Deci, 2017), or performance avoidance goals (Elliot \& McGregor, 2001), a fundamental aspect of a pupil-focused intervention would be to emphasis pupils' own self-referenced psychological need satisfaction, rather than making comparisons with other pupils.

\section{Integration with School Practises}

It also seems impractical to expect a standalone diary-log to provide a meaningful reason for pupils to autonomously engage with the proposed intervention. Pupil engagement may be better facilitated when the initiatives are fused with traditional school practices (see Miltenberger, 2011). Teachers suggested the diary-log could be incorporated into a wider initiative (e.g., culminating in a "showcase event" or "presentation" day) to offer pupils a salient reason to persist with the diary-log, and explained that pupils like being provided with responsibility. Indeed, perceiving personal relevance is a fundamental dimension of experiencing autonomy satisfaction (Katz \& Assor, 2007). Incorporating a showcase event within the school curriculum may help pupils take credit for their improvements, as opposed 


\section{INTRAPSYCHIC PSYCHOLOGICAL NEEDS}

to feeling stigmatised as "being in need" or being overtly aware of the intended outcomes (Yeager \& Walton, 2011), as well as providing a specific timeframe for the intervention rather than it seeming endless. Other extrinsic motives were suggested by pupils, such as specific prizes and merit marks that could be collected to get school awards, but there may be a risk these external contingents could compromise pupils' psychological need satisfaction if their motives became exclusively regulated by such external contingencies (see internalisation process; Deci \& Ryan, 2000).

\section{Limitations and Future Research}

As both teacher and pupil opinions were obtained, they became co-collaborators in developing the intervention as opposed to an initiative being imposed on schools without their input. A limitation of the study, however, is that the sample size was relatively small and limited to two schools. Secondary schools typically comprise large pupil cohorts and it will present a more formidable task to administer the intervention on a larger scale. Future replications of the study may include more schools but focus on a single year group to test the feasibility across a multitude of school institutions. Secondly, despite conscious efforts to recruit a heterogeneous pupil sample, the recruitment method relied on willing teachers consenting to take part, and allowing access to pupils within their classes. Consequently, the present sample may be biased towards teachers that are typically more proactive in piloting new initiatives and pupils that are generally more engaged at school. Nevertheless, although the findings cannot be generalised to pupils that did not volunteer or receive parental consent, the attained responses are useful for informing the applicability of an intervention in schools. Finally, it is acknowledged that the next phase will be to determine the effectiveness of an intervention, such as an electronic version of the diary-log. Using random control group methodologies (e.g. Sherman et al., 2013), future research could test if the proposed 


\section{INTRAPSYCHIC PSYCHOLOGICAL NEEDS}

intervention may help increase pupils' experience of psychological need satisfaction and explore any impact this may have on their well-being and academic performance.

\section{Conclusions}

The present work provides insights into the feasibility of conducting new pupilfocused SDT interventions that could be used to complement existing contextual interventions (e.g., Cheon \& Reeve, 2015). The development of learners' psychological processes has been suggested to have substantial value in facilitating academic progression (Yeager \& Walton, 2011). The present intervention would be aimed at helping pupils become more self-reliant and strive to focus on positive experiences of psychological need satisfaction. Although teachers and pupils could see value in helping pupils become more active in striving for psychological need satisfaction, a written diary-log would appear an unfeasible and ineffective method of engaging pupils in an intervention. Future implementation of a pupil-focused intervention may be more effective by including methods of guiding pupils in their reflection process, being incorporated into normal school practices, and being distinct from routine school work through the use of interactive electronic applications. The present study provides a practical foundation for the development of future SDT interventions and analytical research to examine the validity and effectiveness of pupilfocused initiatives in enhancing pupils' psychological need satisfaction.

\section{Declaration of Interests}

No potential conflict of interest was reported by the authors. 


\section{References}

Aelterman, N., Vansteenkiste, M., Van den Berghe, L., De Meyer, J., \& Haerens, L. (2014). Fostering a need-supportive teaching style: Intervention effects on physical education teachers' beliefs and teaching behaviors. Journal of Sport \& Exercise Psychology, 36(6), 595-609. doi: 10.1123/jsep.2013-0229

Aelterman, N., Vansteenkiste, M., Van Keer, H., De Meyer, J., Van den Berghe, L., \& Haerens, L. (2013). Development and evaluation of a training on need-supportive teaching in physical education: Qualitative and quantitative findings. Teaching and Teacher Education, 29, 64-75. doi: 10.1016/j.tate.2012.09.001

Azevedo, R., Moos, D. C., Johnson, A. M., \& Chauncey, A. D. (2010). Measuring cognitive and metacognitive regulatory processes during hypermedia learning: Issues and challenges. Educational psychologist, 45(4), 210-223. doi:

$10.1080 / 00461520.2010 .515934$

Bakracevic Vukman, K., \& Licardo, M. (2010). How cognitive, metacognitive, motivational and emotional self-regulation influence school performance in adolescence and early adulthood. Educational Studies, 36(3), 259-268 doi:10.1080/03055690903180376

Badri, R., Amani-Saribaglou, J., Ahrari, G., Jahadi, N., \& Mahmoudi, H. (2014). School culture, basic psychological needs, intrinsic motivation and academic achievement: Testing a casual model. Mathematics Education Trends and Research, 4, 1-13. doi: $10.5899 / 2014 /$ metr-00050

Barker, J., \& Weller, S. (2003). "Is it fun?" Developing children centred research methods. International Journal of Sociology and Social Policy, 23(1/2), 33-58. doi: $10.1108 / 01443330310790435$

Baumeister, R.F., \& Leary, M.R. (1995). The need to belong: Desire for interpersonal attachments as a fundamental human motivation. Psychological Bulletin, 117, 497-529. doi:10.1037/0033-2909.117.3.497

Campbell, J. L., Quincy, C., Osserman, J., \& Pedersen, O. K. (2013). Coding in-depth semistructured interviews: Problems of unitization and intercoder reliability and agreement. Sociological Methods \& Research, 42(3), 294-320.

doi:10.1177/0049124113500475 
Carey, M. A., \& Asbury, J. E. (2016). Focus group research. Routledge.

Cheon, S. H., \& Reeve, J. (2013). Do the benefits from autonomy-supportive PE teacher training programs endure? A one-year follow-up investigation. Psychology of Sport and Exercise, 14(4), 508-518. doi: 10.1016/j.psychsport.2013.02.002

Cheon, S. H., \& Reeve, J. (2015). A classroom-based intervention to help teachers decrease students' amotivation. Contemporary Educational Psychology, 40, 99-111. doi:10.1016/j.cedpsych.2014.06.004

Cleary, T. J., \& Zimmerman, B. J. (2004). Self-regulation empowerment program: A schoolbased program to enhance self-regulated and self-motivated cycles of student learning. Psychology in the Schools, 41(5), 537-550. doi: 10.1002/pits.10177

Cohen, L., Manion, L., \& Morrison, K. (2013). Research Methods in Education. Routledge. deCharms, R. (1968). Personal Causation: The Internal Affective Determinants of Behavior. New York, NY: Academic.

Deci, E. L., \& Ryan, R. M. (2000). The "what" and "why" of goal pursuits: Human needs and the self-determination of behavior. Psychological Inquiry: An International Journal for the Advancement of Psychological Theory, 11, 319-338. doi:10.1207/S15327965PLI1104_01

Deci, E. L., Ryan, R. M., \& Williams, G. C. (1996). Need satisfaction and the self-regulation of learning. Learning and Individual Differences, 8(3), 165-183. doi:10.1016/S10416080(96)90013-8

Department of Education (2019). Character education framework. London: Department of Education. Retrieved January 5, 2020 from https://www.gov.uk/government/publications/character-education-framework.

Duckworth, A. L., White, R. E., Matteucci, A. J., Shearer, A., \& Gross, J. J. (2016). A stitch in time: Strategic self-control in high school and college students. Journal of Educational Psychology, 108(3), 329-341. doi:10.1037/edu0000062

Earl, S. R., Taylor, I. M., Meijen, C., \& Passfield, L. (2017). Autonomy and competence frustration in young adolescent classrooms: different associations with active and passive disengagement. Learning and Instruction, 49, 32-40. doi:

10.1016/j.learninstruc.2016.12.001

Elliot, A. J., \& McGregor, H. A. (2001). A $2 \times 2$ achievement goal framework. Journal of personality and social psychology, 80(3), 501. doi: 10.1037/0022-3514.80.3.501 
Ghanizadeh, A. (2017). The interplay between reflective thinking, critical thinking, selfmonitoring, and academic achievement in higher education. Higher Education, 74(1), 101-114. doi:10.1007/s10734-016-0031-y

Glogger, I., Schwonke, R., Holzäpfel, L., Nückles, M., \& Renkl, A. (2012). Learning strategies assessed by journal writing: Prediction of learning outcomes by quantity, quality, and combinations of learning strategies. Journal of educational psychology, 104(2), 452. doi:10.1037/a0026683

Grant, A., Kinnersley, P., Metcalf, E., Pill, R., \& Houston, H. (2006). Students' views of reflective learning techniques: an efficacy study at a UK medical school. Medical Education, 40(4), 379-388. doi:10.1111/j.1365-2929.2006.02415.x

Henshaw, P. (2017). Concern that schools are not preparing for new data rules. Seced, 2017(18), 1-1. doi:10.12968/sece.2017.18.1

Holland, C., \& Muilenburg, L. (2011). Supporting student collaboration: Edmodo in the classroom. In Society for Information Technology \& Teacher Education International Conference, 1, 3232-3236. Retrieved from https://www.learntechlib.org/p/36816.

Hospel, V., \& Galand, B. (2016). Are both classroom autonomy support and structure equally important for students' engagement? A multilevel analysis. Learning and Instruction, 41, 1-10. doi:10.1016/j.learninstruc.2015.09.001

Hudley, C., Graham, S., \& Taylor, A. (2007). Reducing aggressive behavior and increasing motivation in school: The evolution of an intervention to strengthen school adjustment. Educational Psychologist, 42(4), 251-260. doi:10.1080/00461520701621095

Huizinga, M., Dolan, C. V., \& van der Molen, M. W. (2006). Age-related change in executive function: Developmental trends and a latent variable analysis. Neuropsychologia, 44(11), 2017-2036. doi: 10.1016/j.neuropsychologia.2006.01.010

Jang, H., Kim, E. J., \& Reeve, J. (2016). Why students become more engaged or more disengaged during the semester: A self-determination theory dual-process model. Learning and Instruction. 43, 27-38. doi: 10.1016/j.learninstruc.2016.01.002

Johnson, G., \& Davies, S. (2014). Self-regulated learning in digital environments: Theory, research, praxis. British Journal of Research, 1(2), 1-14. Accessed at www.britishjr.org

Katz, I., \& Assor, A. (2007). When choice motivates and when it does not. Educational Psychology Review, 19(4), 429-442. doi: 10.1007/s10648-006-9027-y 
Krueger, R. A., \& Casey, M. A. (2014). Focus groups: A practical guide for applied research. Sage publications.

Lawson, M. A., \& Lawson, H. A. (2013). New conceptual frameworks for student engagement research, policy, and practice. Review of Educational Research, 83(3), 432479. doi:10.3102/0034654313480891

Legault, L., Green-Demers, I., \& Pelletier, L. (2006). Why do high school students lack motivation in the classroom? Toward an understanding of academic amotivation and the role of social support. Journal of Educational Psychology, 98, 567-582. doi:10.1037/0022-0663.98.3.567

Levesque, C., Copeland, K. J., \& Sutcliffe, R. A. (2008). Conscious and nonconscious processes: Implications for self-determination theory. Canadian Psychology/Psychologie canadienne, 49(3), 218. doi:10.1037/a0012756

Liu, W. C., Wang, C. J., Reeve, J., Kee, Y. H., \& Chian, L. K. (2019). What Determines Teachers' Use of Motivational Strategies in the Classrooms? A Self-Determination Theory Perspective. Journal of Education. doi: 10.1177/0022057419881171

Lyst, A. M., Gabriel, S., O'Shaughnessy, T. E., Meyers, J., \& Meyers, B. (2005). Social validity: Perceptions of check and connect with early literacy support. Journal of School Psychology, 43(3), 197-218. doi: 10.1016/j.jsp.2005.04.004

Martin, F., \& Ertzberger, J. (2013). Here and now mobile learning: An experimental study on the use of mobile technology. Computers \& Education, 68, 76-85. doi:10.1016/j.compedu.2013.04.021

McLean, K. C., Breen, A. V., \& Fournier, M. A. (2010). Constructing the Self in Early, Middle, and Late Adolescent Boys: Narrative Identity, Individuation, and Well-Being. Journal of Research on Adolescence, 20(1), 166-187. doi: 10.1111/j.15327795.2009.00633.x

Mendelson, T., Greenberg, M. T., Dariotis, J. K., Gould, L. F., Rhoades, B. L., \& Leaf, P. J. (2010). Feasibility and preliminary outcomes of a school-based mindfulness intervention for urban youth. Journal of Abnormal Child Psychology, 38(7), 985-994. doi: 10.1007/s10802-010-9418-x

Miltenberger, R. G. (2011). Behavior modification: Principles and procedures. Cengage Learning. 
Milyavskaya, M., \& Koestner, R. (2011). Psychological needs, motivation, and well-being: A test of self-determination theory across multiple domains. Personality and Individual Differences, 50(3), 387-391. doi:10.1016/j.paid.2010.10.029

Morse, J. M., \& Mitcham, C. (2002). Exploring qualitatively-derived concepts: Inductivedeductive pitfalls. International Journal of Qualitative Methods, 1(4), 28-35. doi:10.1177/160940690200100404\#

Park, D., Gunderson, E. A., Tsukayama, E., Levine, S. C., \& Beilock, S. L. (2016). Young children's motivational frameworks and math achievement: Relation to teacher-reported instructional practices, but not teacher theory of intelligence. Journal of Educational Psychology, 108(3), 300-313. doi:10.1037/edu0000064

Patton, M. Q. (2002). Two decades of developments in qualitative inquiry a personal, experiential perspective. Qualitative Social Work, 1(3), 261-283. doi:10.1177/1473325002001003636

Pavlovich, K. (2007). The development of reflective practice through student journals. Higher Education Research \& Development, 26(3), 281-295. doi:10.1080/07294360701494302

Pelletier, L. G., Séguin-Lévesque, C., \& Legault, L. (2002). Pressure from above and pressure from below as determinants of teachers' motivation and teaching behaviors. Journal of Educational Psychology, 94(1), 186-196. doi.org/10.1037/00220663.94.1.186

Ratelle, C. F., \& Duchesne, S. (2014). Trajectories of psychological need satisfaction from early to late adolescence as a predictor of adjustment in school. Contemporary Educational Psychology, 39(4), 388-400. doi:10.1016/j.cedpsych.2014.09.003

Rawson, K., Stahovich, T. F., \& Mayer, R. E. (2017). Homework and achievement: Using smartpen technology to find the connection. Journal of Educational Psychology, 109(2), 208-219. doi:10.1037/edu0000130

Reeve, J., \& Cheon, S. H. (2016). Teachers become more autonomy supportive after they believe it is easy to do. Psychology of Sport and Exercise, 22, 178-189. doi:10.1016/j.psychsport.2015.08.001

Reeve, J., \& Jang, H. (2006). What teachers say and do to support students' autonomy during a learning activity. Journal of Educational Psychology, 98(1), 209-218. doi: 10.1037/0022-0663.98.1.209 
Reeve, J., Jang, H., Carrell, D., Jeon, S., \& Barch, J. (2004). Enhancing students' engagement by increasing teachers' autonomy support. Motivation and Emotion, 28(2), 147-169. doi: 10.1023/B:MOEM.0000032312.95499.6f

Reeve, J., Nix, G., \& Hamm, D. (2003). Testing models of the experience of selfdetermination in intrinsic motivation and the conundrum of choice. Journal of Educational Psychology, 95(2), 375. doi. 10.1037/0022-0663.95.2.375

Ruzek, E. A., Hafen, C. A., Allen, J. P., Gregory, A., Mikami, A. Y., \& Pianta, R. C. (2016). How teacher emotional support motivates students: The mediating roles of perceived peer relatedness, autonomy support, and competence. Learning and Instruction, 42, 95103. doi:10.1016/j.learninstruc.2016.01.004

Ryan, R. M., \& Deci, E. L. (2017). Self-determination theory: Basic psychological needs in motivation, development, and wellness. New York: Guilford Publishing.

Saeki, E., \& Quirk, M. (2015). Getting students engaged might not be enough: the importance of psychological needs satisfaction on social-emotional and behavioral functioning among early adolescents. Social Psychology of Education, 18(2), 355-371. doi: 10.1007/s11218-014-9283-5

Schmid, K. L., Phelps, E., \& Lerner, R. M. (2011). Constructing positive futures: Modeling the relationship between adolescents' hopeful future expectations and intentional self regulation in predicting positive youth development. Journal of adolescence, 34(6), 1127-1135. doi: 10.1016/j.adolescence.2011.07.009

Shannon, S., Brennan, D., Hanna, D., Younger, Z., Hassan, J., \& Breslin, G. (2018). The Effect of a School-Based Intervention on Physical Activity and Well-Being: a NonRandomised Controlled Trial with Children of Low Socio-Economic Status. Sports medicine-open, 4(1), 16-29. doi: 10.1186/s40798-018-0129-0

Sherman, D. K., Hartson, K. A., Binning, K. R., Purdie-Vaughns, V., Garcia, J., TaborskyBarba, S., ... \& Cohen, G. L. (2013). Deflecting the trajectory and changing the narrative: how self-affirmation affects academic performance and motivation under identity threat. Journal of Personality and Social Psychology, 104(4), 591-618. doi: 10.1037/a0031495

Spencer, K. M., Coutts, T., Fagan, T., \& King, A. (2013). Connections, diversity, coherence: three vignettes exploring learning with ipads in primary schools. Comput. NZ Sch.: Learn., Teach., Technol, 25(1-3), 38-55. Retrieved from www.otago.ac.nz/cdelt/otago065355.pdf 
Stevenson, M., Hedberg, J., Highfield, K., \& Diao, M. (2015). Visualizing solutions: Apps as cognitive stepping-stones in the learning process. Electronic Journal of e-Learning, 13(5), 366-379. Available at www.ejel.org.

Stewart, D. W., \& Shamdasani, P. N. (2014). Focus groups: Theory and practice (Vol. 20). Sage publications.

Taylor, I. M., \& Ntoumanis, N. (2007). Teacher motivational strategies and student selfdetermination in physical education. Journal of Educational Psychology, 99(4), 747 760. doi: 10.1037/0022-0663.99.4.747

Taylor, I. M., Ntoumanis, N. \& Smith, B. (2009). The social context as a determinant of teacher motivational strategies in physical education. Psychology of Sport and Exercise, 10, 235-243. doi:10.1016/j.psychsport.2008.09.002

Tessier, D., Sarrazin, P., \& Ntoumanis, N. (2010). The effect of an intervention to improve newly qualified teachers' interpersonal style, students' motivation and psychological need satisfaction in sport-based physical education. Contemporary Educational Psychology, 35(4), 242-253. doi: 10.1016/j.cedpsych.2010.05.005

Travagin, G., Margola, D., \& Revenson, T. A. (2015). How effective are expressive writing interventions for adolescents? A meta-analytic review. Clinical psychology review, 36, 42-55. doi: 10.1016/j.cpr.2015.01.003

Vaismoradi, M., Turunen, H., \& Bondas, T. (2013). Content analysis and thematic analysis: Implications for conducting a qualitative descriptive study. Nursing $\&$ health sciences, 15(3), 398-405. doi: 10.1111/nhs.12048

Walshe, N. (2013). Exploring and developing children's understandings of sustainable development with dialogic diaries. Children's Geographies, 11(1), 132-154. doi: 10.1080/14733285.2013.743286

Ward, S., \& Sweeney, S. (2015). Apps That Help Students 'Get It Done': Looking to support students with executive-functioning problems? These apps aid regulation, situational awareness, planning and time management. The ASHA Leader, 20(5), online-only. Accessed at www.leader.pubs.asha.org

White, R. W. (1959). Motivation reconsidered: The concept of competence. Psychological Review, 66, 297-333. doi:10.1037/ h0040934

Yeager, D. S., \& Walton, G. M. (2011). Social-psychological interventions in education They're not magic. Review of Educational Research, 81(2), 267-301. doi:

$10.3102 / 0034654311405999$ 


\section{INTRAPSYCHIC PSYCHOLOGICAL NEEDS}

Zaborowski, K. U., \& Breidenstein, G. (2011). Disciplinary technologies and pupil redisposition: school equipment and homework diaries. Ethnography and Education, 6(2), 147-160. doi: 10.1080/17457823.2011.587355

Zeedyk, M. S., Gallacher, J., Henderson, M., Hope, G., Husband, B., \& Lindsay, K. (2003). Negotiating the transition from primary to secondary school perceptions of pupils, parents and teachers. School Psychology International, 24(1), 67-79. doi: $10.1177 / 0143034303024001010$

Zimmerman, B. J. (2008). Investigating self-regulation and motivation: Historical background, methodological developments, and future prospects. American educational research journal, 45(1), 166-183. doi:10.3102/0002831207312909 
Figure 1

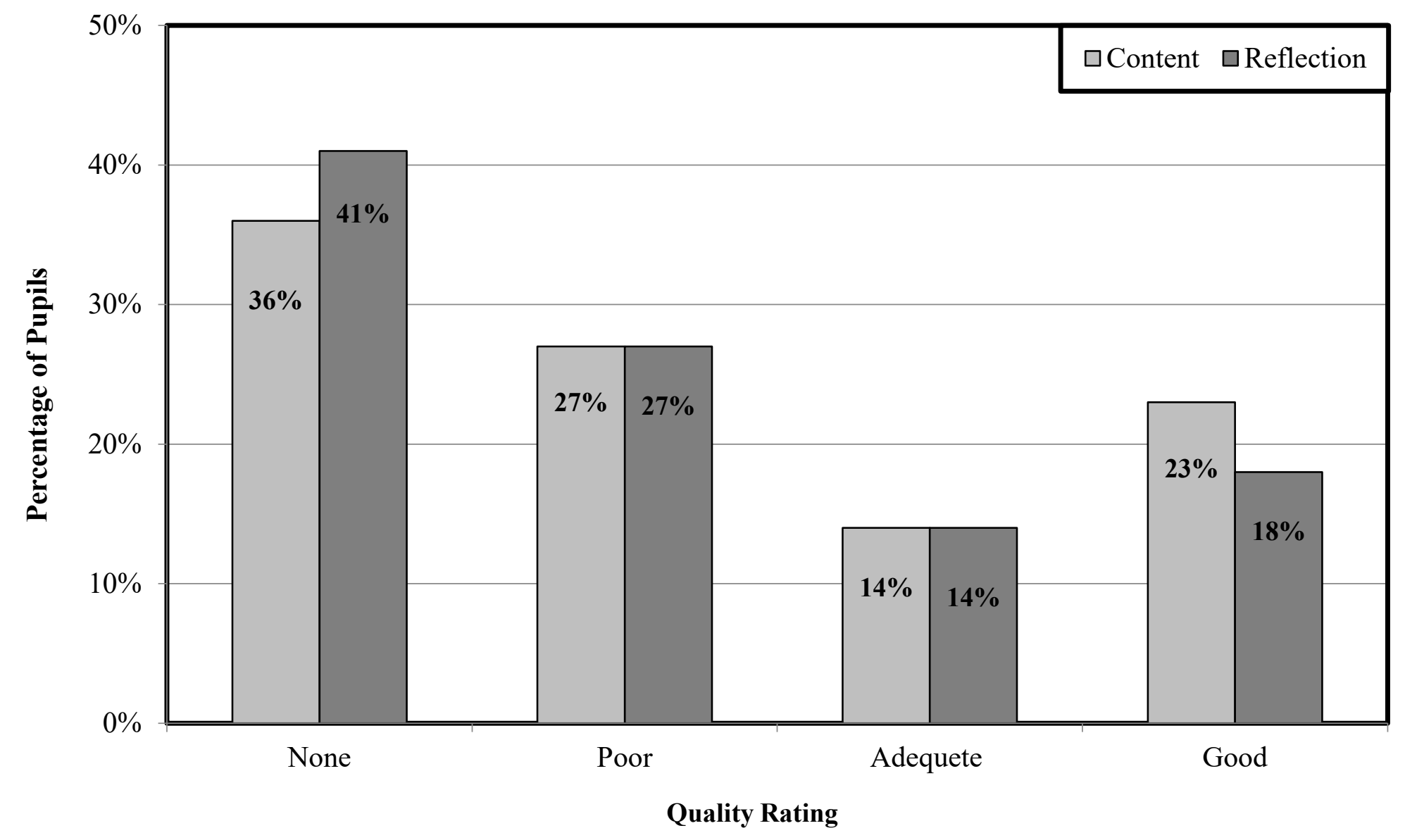


INTRAPSYCHIC PSYCHOLOGICAL NEEDS

Figure 2

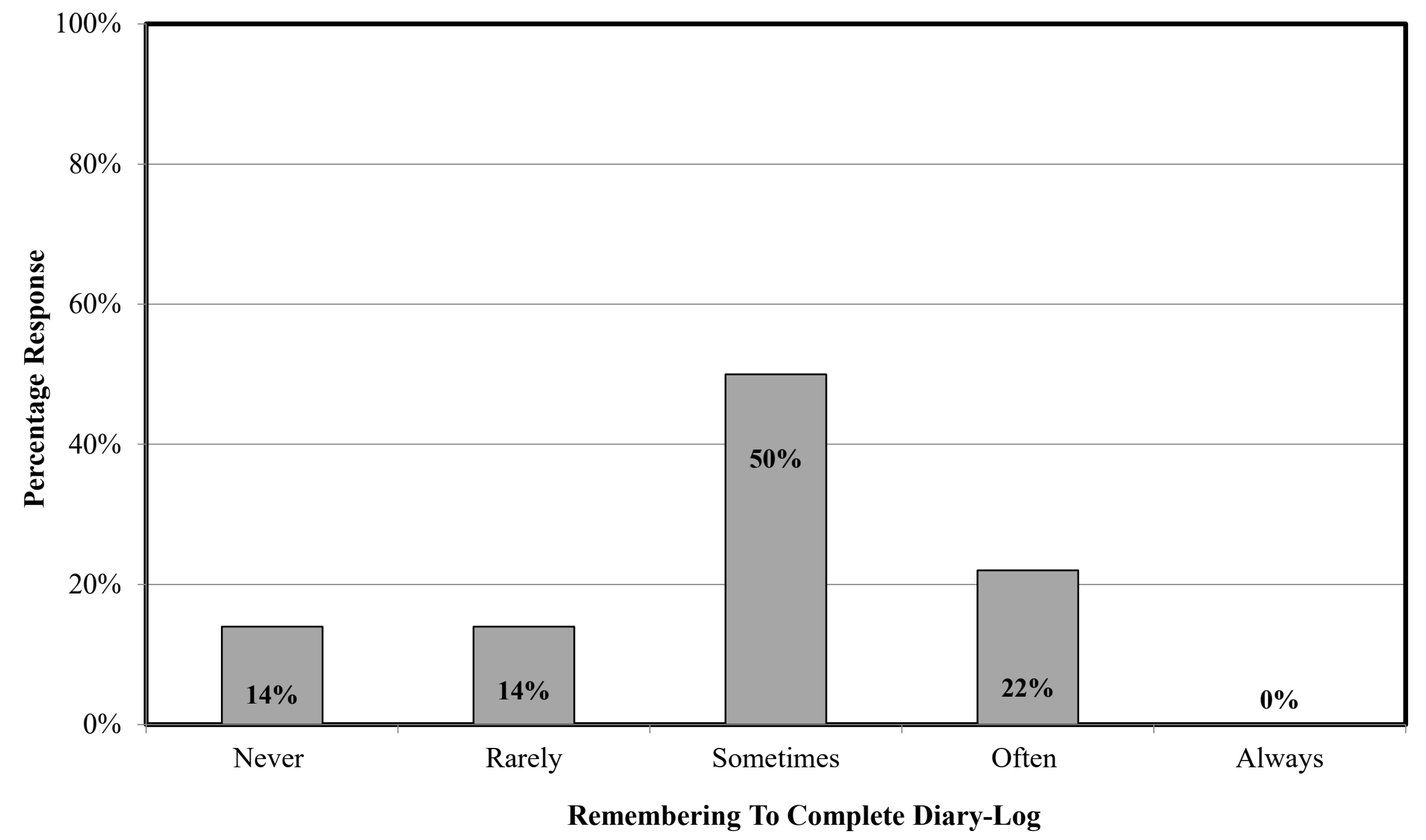


INTRAPSYCHIC PSYCHOLOGICAL NEEDS

Figure 3

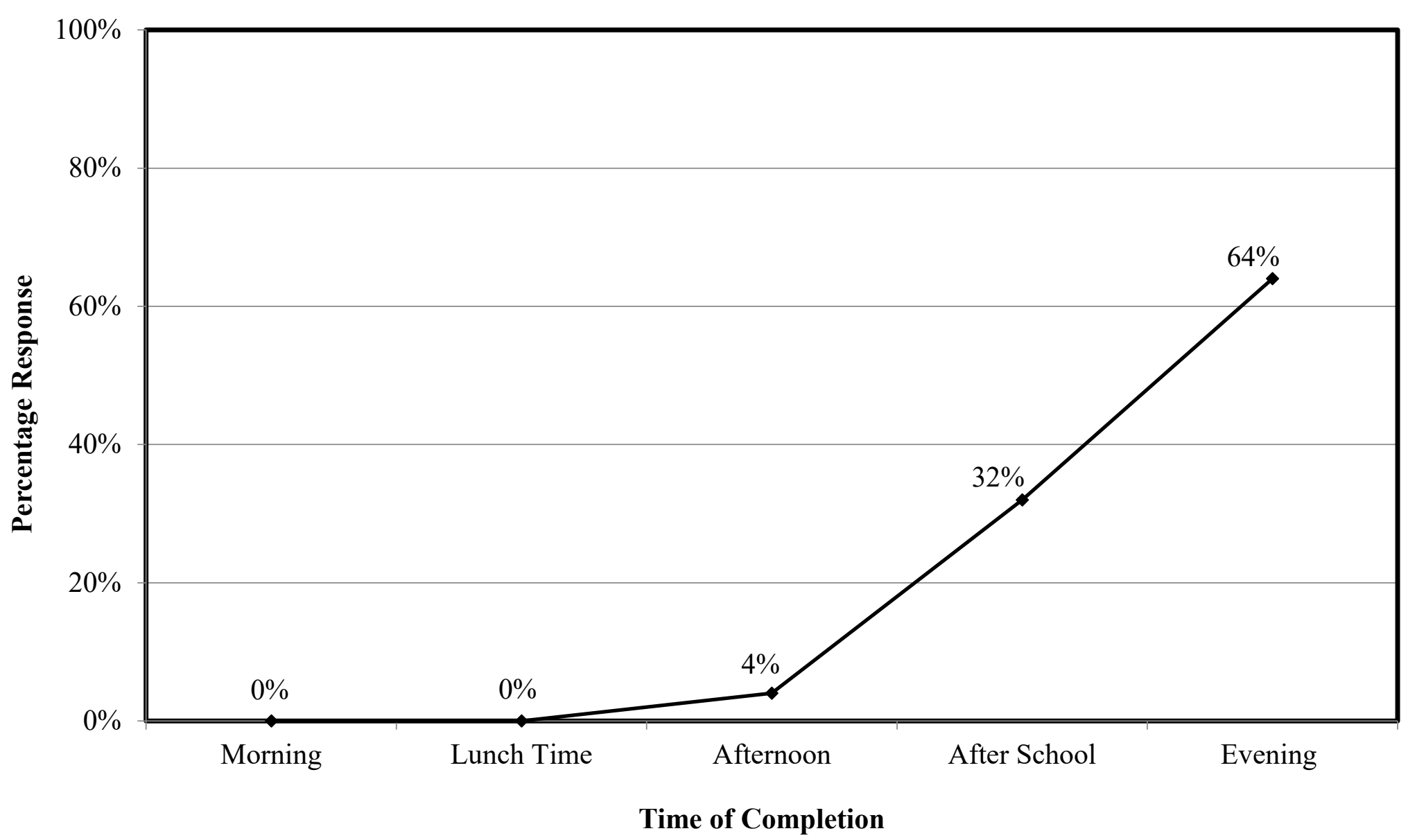




\section{INTRAPSYCHIC PSYCHOLOGICAL NEEDS}

\section{Figure Subscripts}

Figure 1. The percentage number of pupil diary-logs rated in written content and reflection quality $(\mathrm{N}=22)$.

Figure 2. The percentage number of pupils reporting the extent they remembered to complete the diary-log $(\mathrm{N}=22)$.

Figure 3. The time of day pupils reported they typically completed the diary-log $(\mathrm{N}=22)$. 


\section{$\underline{\text { Supplementary Information }}$}

\section{Activity Diary}

$i$ The aim of this diary is to help you record and remember times that you felt you were good at something, and/or worked well with others.

is You can complete the diary at any time you wish.

it The questions in orange are about things you felt you were good at, and the boxes in blue are about times you felt you worked well with others.

$>$ The activity you felt you were good at can be different from the activity when you worked well with others.

> Some days you may only complete one set of questions. For example, you may only be able think of something you were good at, but not a time when you worked well with others.

is The dairy is organised into 3 sections:

Morning Lesson: This can be something from a particular morning lesson, or a mixture of things from different morning lessons.

$>$ Afternoon Lesson: This can be something from a particular afternoon lesson, or a mixture of things from different afternoon lessons.

Other Activities: These can be things that you did outside of lessons at school (e.g. lunchtime, after school clubs, sport sessions), or activities you do in your own free time (e.g. spending time with friends).

is You do not have to complete every section. For example, some days you may write a lot for the morning lesson, but very little for the afternoon lesson.

is On days when you feel you may not have much to write at all, you can still try to think of something you did well or enjoyed on that day. These may be things that you don't normally think of (e.g. being on time for a lesson or helping someone).

Don't feel that you have to write something every day. There may be days when you have a lot more to write than other days, so don't worry if you leave some days blank. 


\section{Helpful Tips}

1. For the questions - "What were you good at?" and "When did you work well with others?" - Describe the activity that you did.

Example: "I thought I did really well today in Maths today. We were learning about fractions".

Example: "In my Science lesson today, I helped someone understand the task as they didn't understand what we had to do".

2. For the questions "How did you feel?" - Just write the feelings you felt.

Some examples may be:

$\begin{array}{ll}\text { Happy } & \text { Capable } \\ \text { Determined } & \text { Supportive } \\ \text { Inspired } & \text { Excited } \\ \text { Comfortable } & \text { Proud } \\ \text { Relaxed } & \text { Respectful } \\ \text { Energetic } & \text { Friendly } \\ \text { Pleased } & \text { Confident } \\ \text { Glad } & \text { Calm }\end{array}$

3. For the questions "Why did you feel like this?" - Explain the specific things that made you feel that way.

D Example: "I felt determined to answer all the questions we were set in the lesson, and was proud that I got more correct than I did last lesson". Example: "I felt supportive because I was able to help my friend, otherwise they might not have done the activity".

\section{(An example diary is presented on the next page to help you)}




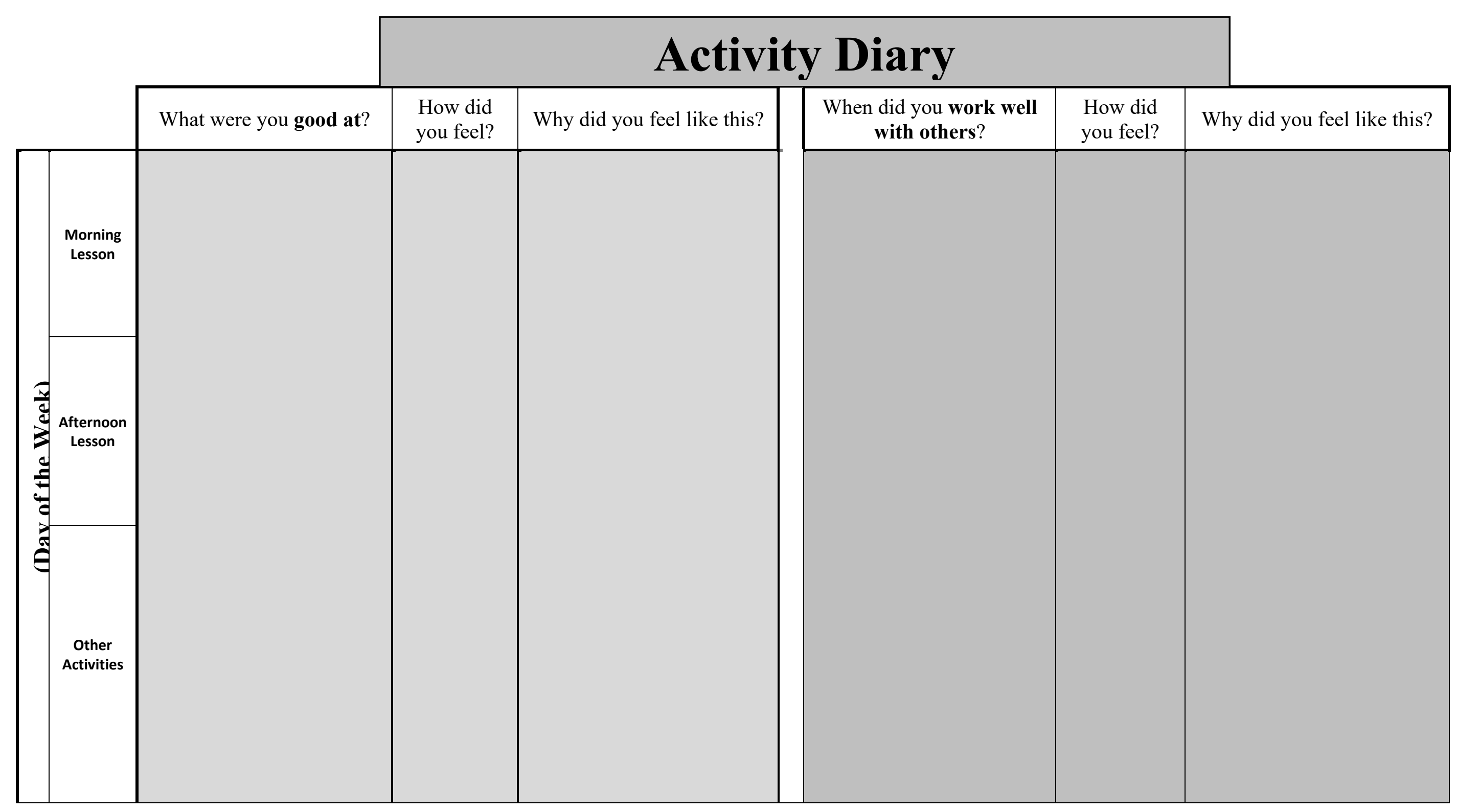

